\title{
ESTUDO DOS MÚLTIPLOS E DIVISORES POR MEIO DE RESOLUÇÃO DE PROBLEMAS: UM RELATO DE EXPERIÊNCIA DOCENTE
}

\section{STUDY OF MULTIPLES AND DIVISORS BY USING THE PROBLEM SOLVING APPROACH: REPORT OF A TEACHING EXPERIENCE}

\author{
Danilo Augusto Ferreira de Jesuz ${ }^{1}$ \\ Ana Lúcia Pereira ${ }^{2}$
}

\begin{abstract}
Resumo: O presente artigo relata uma experiência realizada por um dos autores referente ao ensino de múltiplos, divisores, números primos e quadrados perfeitos em uma turma do sétimo ano do ensino fundamental em uma escola pública do município de Siqueira Campos, PR. As tarefas desenvolvidas foram baseadas no modelo de Resolução de Problemas proposto por Polya, em que os alunos são estimulados a participarem ativamente no processo de aprendizagem. A principal lição extraída dessa experiência foi a efetividade desse método em aprimorar o raciocínio lógico e a criatividade entre os alunos, além de aprimorar a capacidade dos mesmos em trabalhar em grupo para resolver problemas mais desafiadores.
\end{abstract}

Palavras-chave: Múltiplos; Divisores; Relato de experiência; Resolução de Problemas.

\begin{abstract}
The present article reports an experience carried out by one of the authors on teaching multiples, divisors, prime numbers and perfect squares to a 7 th year class of the fundamental level in a public school in the City of Siqueira Campos, State of Parana, Brazil. The developed activities were based on the Polya's model of problem solving, in which the pupils are stimulated to participate actively in the learning process. The main lesson drawn from this experience was the effectiveness of this method in fostering the logical reasoning and creativity among the pupils, as well as in fostering their ability to work in group to solve more challenging problems.
\end{abstract}

Keywords: Multiples; Dividers; Exploratory Teaching; Problem Solving.

\section{Introdução}

No início do ano letivo de 2016, dentre as opções de turmas para lecionar Matemática, um dos autores deste artigo optou por trabalhar com uma turma de $7^{\circ}$ ano do Ensino Fundamental, de uma Escola Pública na cidade de Siqueira Campos - PR. Ao fazer um diagnóstico inicial da turma constatamos que a maioria dos alunos encontravase desmotivada em relação aos estudos e apresentava certa defasagem em relação aos conteúdos de matemática, e por conta disso tumultuava as aulas com conversas e brincadeiras inconvenientes.

\footnotetext{
${ }^{1}$ Doutorando em Educação pela Universidade Estadual de Ponta Grossa (UEPG). Professor do Institudo Federal do Paraná (IFPR), Paraná, Brasil. E-mail: danilo.jesuz@ifpr.edu.br

${ }^{2}$ Doutora em Ensino de Ciências e Educação Matemática pela Universidade Estadual de Londrina (UEL). Professora da Universidade Estadual de Ponta Grossa (UEPG), Ponta Grossa, Paraná, Brasil. E-mail: ana.lucia.pereira.173@gmail.com
} 
Além disso, percebemos também que os alunos não tinham autonomia para realizar as tarefas ${ }^{3}$ a eles designadas. Avaliamos que era natural para a turma aprender matemática a partir de explicações do professor, principalmente por meio de exemplos e posteriormente apresentar exercícios semelhantes para que eles resolvessem. Qualquer proposta que escapasse a essa rotina mostrava-se complexapara os alunos que se propunham a estudar.

De acordo com os Parâmetros Curriculares Nacionais (PCN), documento de suporte para o trabalho docente no Brasil, tradicionalmente as aulas de matemática tendem a seguir um padrão que consiste na centralização do ensino no professor, ou seja, geralmente as aulas são de caráter expositivo e o professor é visto como transmissor do conteúdo, partindo de definições, demonstrações de propriedades e exemplificação, para posteriormente propor aos alunos exercícios de fixação, que serão corrigidos na lousa (BRASIL, 1998). Entretanto, os PCN apresentam sua posição contrária em relação à concepção de ensino de matemática pautada em aulas expositivas, considerando-a uma prática de ensino ineficaz, visto que a partir dela o aluno terá condições apenas de reproduzir alguns procedimentos de forma mecânica e descontextualizada e, possivelmente, não seja capaz de aplicar os conceitos em outras situações, visto que não aprendeu de fato o conteúdo (BRASIL, 1998).

Podemos destacar que observamos características dessa concepção de ensino enraizada na aprendizagem dos alunos da referida turma, pois os poucos alunos que demonstravam interesse nos estudos estavam acostumados a esses "modelos clássicos" (PARANÁ, 2008). Percebemos que os alunos precisavam ser estimulados ao desenvolvimento de um trabalho autônomo e criativo, fato que demanda a busca por alternativas metodológicas.Acreditamos que existem alternativas além das aulas expositivas e centralizadas no docente, e que estas podem trazer benefícios para a aprendizagem, à medida que contemplema participação ativa do aluno no processo de ensino e aprendizagem.

Nessa perspectiva, os PCN orientam a organização de um trabalho docente que considere o aluno como protagonista no processo de construção de sua aprendizagem e, para tanto, o docente deve conhecer as condições socioculturais, expectativas e competência cognitiva dos alunos, além de escolher adequadamente os problemas que possibilitem o desenvolvimento de tal proposta (BRASIL, 1998).

${ }^{3}$ Em nossa proposta, utilizamos o termo tarefas na concepção de elemento organizador do processo pedagógico, que pode motivar o desenvolvimento de atividade do aluno (PONTE, 2014). 
$\mathrm{Na}$ busca por alternativas e repensando o planejamento docente com vistas a atender as necessidades específicas dos alunos dessa turma do $7^{\circ}$ ano, surgiu a proposta que estamos apresentando neste artigo por meio de relato de experiência, que se caracterizou por mudança na dinâmica das aulas, visto que propusemos o estudo de um conteúdo por meio da Resolução de Problemas, com base no Modelo de George Polya.

\section{A resolução de problemas como uma proposta metodológia}

Conforme destacamos acima, na busca por alternativas que viessem ao encontro de apresentar um ensino diferenciado e que envolvesse de fato os alunos para além do "siga o modelo", optamos pelo modelo de Resolução de Problemas apresentada por Polya (1994).

A Resolução de Problemas é considerada pelas Diretrizes Curriculares da Educação Básica de Matemática, como uma das "tendências metodológicas da Educação Matemática que fundamentam a prática docente" (PARANÁ, 2008, p. 63).

George Polya em seu livro A Arte de Resolver Problemas apresenta um modelo para resolução de problemas que é o composto por quatro etapas: Compreensão do Problema ${ }^{4}$; Estabelecimento de um Plano; A Execução do Plano e o Retrospecto. No Quadro 1 apresentamosas principais características de cada uma das etapas do modelo de Resolução de Problemas apresentado por Polya (1994), bem como as funções de docente e discentes durante o desenvolvimento das etapas.

\begin{tabular}{|c|c|c|}
\hline Etapa & Papel do Estudante & Papel do Professor \\
\hline \multirow[b]{2}{*}{$\begin{array}{l}\text { Compreensão do } \\
\text { problema }\end{array}$} & $\begin{array}{l}\text { Familiarização: } \mathrm{O} \text { estudante } \\
\text { compreende o problema de forma } \\
\text { geral, considerando seus objetivos e } \\
\text { informações relevantes. }\end{array}$ & \multirow[b]{2}{*}{$\begin{array}{l}\text { A função do professor se inicia com a boa } \\
\text { escolha do problema que irá propor, de } \\
\text { forma que os estudantes tenham interesse } \\
\text { em resolvê-lo. Segundo o autor, o } \\
\text { problema deve ser natural e interessante, } \\
\text { nem muito simples e nem muito } \\
\text { complexo. }\end{array}$} \\
\hline & $\begin{array}{l}\text { Aperfeiçoamento da compreensão:O } \\
\text { estudante consegue explicar o } \\
\text { enunciado com suas próprias palavras } \\
\text { e tem o problema claro em sua } \\
\text { mente.Nessa fase deve considerar o } \\
\text { problema por vários pontos de vista e, } \\
\text { se for o caso, relacioná-lo a uma } \\
\text { imagem, indicar a incógnita, coletar } \\
\text { os dados e as informações } \\
\text { importantes. }\end{array}$ & \\
\hline
\end{tabular}

\footnotetext{
${ }^{4}$ Trabalhamos com a concepção de Van de Walle (2009, p. 57) onde problema é qualquer tarefa na qual os "estudantes não tenham nenhum método ou regra já receitados ou memorizados e nem haja uma percepção por parte dos estudantes de que haja um método "correto" específico de solução".
} 


\begin{tabular}{|c|c|c|}
\hline $\begin{array}{l}\text { O } \\
\text { estabelecimento } \\
\text { de um plano }\end{array}$ & $\begin{array}{l}\text { Elaborar um plano para tentar } \\
\text { resolver o problema proposto. Ao } \\
\text { elaborar o plano, o estudante } \\
\text { distingue o que fará em cada um dos } \\
\text { passos desse plano, quais estratégias } \\
\text { serão utilizadas e quais objetivos } \\
\text { conseguirá atingir ao desenvolver } \\
\text { essas estratégias. }\end{array}$ & $\begin{array}{l}\text { "O caminho que vai desde a compreensão } \\
\text { do problema até o estabelecimento de um } \\
\text { plano, pode ser longo e tortuoso" } \\
\text { (POLYA, 1994, p.5). Nesse contexto o } \\
\text { professor pode fazer questionamentos que } \\
\text { possibilitem que o estudante estabeleça o } \\
\text { seu plano.Para orientar o aluno, o } \\
\text { professor pode basear-se nas suas próprias } \\
\text { experiências, dificuldades e desafios } \\
\text { encontrados ao resolver problemas. O } \\
\text { autor também destaca que os } \\
\text { conhecimentos matemáticos já adquiridos } \\
\text { são fundamentais para o bom êxito na } \\
\text { resolução do problema. Nesse aspecto, } \\
\text { uma possibilidade é a proposição de um } \\
\text { problema correlato, cuja resolução os } \\
\text { alunos já conheçam ou tenham condições } \\
\text { de resolvê-lo e posteriormente relacioná- } \\
\text { lo com o problema inicial. }\end{array}$ \\
\hline $\begin{array}{l}\text { Execução } \quad d o \\
\text { Plano }\end{array}$ & $\begin{array}{l}\text { O estudante deverá colocar em prática } \\
\text { as estratégias traçadas na etapa } \\
\text { anterior. }\end{array}$ & $\begin{array}{l}\text { Se o estudante realmente houver } \\
\text { concebido um plano, o professor terá } \\
\text { então um período de relativa } \\
\text { tranquilidade. }\end{array}$ \\
\hline Retrospecto & $\begin{array}{l}\text { Os estudantes têm a oportunidade de } \\
\text { analisar o problema, revisando cada } \\
\text { uma das fases, desde a compreensão } \\
\text { do problema até a resposta, } \\
\text { verificando também se a resolução é } \\
\text { coerente e se responde à questão } \\
\text { central levantada no problema. }\end{array}$ & $\begin{array}{l}\text { Na fase do retrospecto os estudantes } \\
\text { devem procurar rever suas soluções, } \\
\text { conferindo se existem erros, se for } \\
\text { possível, conferir os resultados, analisar se } \\
\text { existem maneiras diferentes para resolvê- } \\
\text { lo e buscar relacioná-lo com outros } \\
\text { problemas e/ou conceitos matemáticos. }\end{array}$ \\
\hline
\end{tabular}

Polya (1994) entende que a função dos problemas nas aulas de matemática é fazer com que o aluno se sinta desafiado em suas habilidades matemáticas e, como decorrência do desafio, experimente o gosto pela descoberta. O autor destaca ainda que por meio de problemas os alunos podem conhecer a verdadeira natureza da matemática e desenvolver afinidade pela disciplina.

Nesse sentido, Schoenfeld (1997) também enfatiza que a Resolução de Problemas possibilita ao aluno construir uma visão diferenciada sobre o conhecimento matemático, visto que este pode ser apreendido no processo de ensino e aprendizagem, pois os alunos têm a oportunidade de compreender os argumentos matemáticos.

Portanto, acreditamos que a metodologia de Resolução de Problemas, apresentada por Polya (1994), pode ser a alternativa para superarmos o ensino caracterizado como tradicionalista, bem como uma nova perspectiva para superarmos a situação de desestímulo de aprendizagem que encontramos na turma do $7^{\circ}$ ano. 


\section{Desenvolvimento da proposta articulado às técnicas de Resolução de Problemas}

Um aspecto que nos chamou atenção na turma do $7^{\circ}$ ano foi que alguns dos alunos procuravam trazer desafios ${ }^{5}$ para o novo professor de Matemática. Os desafios que traziam envolviam questões de raciocínio ou problemas relacionados a conceitos de Matemática. Nos envolvemos com a situação proposta de tal forma, que respondíamos à pergunta e já deixávamos outra, buscando envolver toda a turma. Tais episódios se tornaram rotina nas aulas de Matemática e sempre no início da aula os alunos perguntavam qual seria o desafio do dia. Os desafios propostos eram inicialmente diários e logo se tornaram semanais.

O envolvimento que os alunos demonstraram na resolução dos problemas norteou o estabelecimento de nosso planejamento, partindo de um problema (na concepção deles - desafio) para estimular o estudo de um novo conteúdo, vislumbrando mudar a rotina a que estavam acostumados: aulas expositivas, apresentação de exemplos e proposição de exercícios que estimulam a reprodução de modelos.

Analisamos que seria necessário desenvolver técnicas de resolução de problemas, visto que os alunos apresentavam algumas dificuldades e, portanto, nos apoiamos no Modelo de Polya para a resolução de problemas.

Apresentamos no Quadro 2 abaixo o cronograma com as respectivas datas, números de aulas, encaminhamentos e descrição de como a proposta foi desenvolvida.

\begin{tabular}{|c|c|c|c|}
\hline Aula & Data & Encaminhamentos & Descrição \\
\hline 1 & $06 / 04$ & $\begin{array}{l}\text { Lançamento e familiarização com o } \\
\text { problema. }\end{array}$ & $\begin{array}{l}\text { O problema foi narrado aos alunos com o objetivo de } \\
\text { motivá-los. }\end{array}$ \\
\hline 2 & \multirow[t]{2}{*}{$07 / 04$} & \multirow{2}{*}{$\begin{array}{l}\text { Aperfeiçoamento da compreensão do } \\
\text { problema e início do estabelecimento } \\
\text { de um plano para resolvê-lo. }\end{array}$} & \multirow{5}{*}{$\begin{array}{l}\text { Proposição de outras tarefas e problemas, com o } \\
\text { propósito de que o aluno explore o conceito } \\
\text { trabalhado e que possa construir a formalização de } \\
\text { novos conceitos que se relacionam com o problema } \\
\text { proposto inicialmente. }\end{array}$} \\
\hline 3 & & & \\
\hline 4 & \multirow{2}{*}{ 08/04 } & \multirow{3}{*}{ Estabelecimento de um plano. } & \\
\hline 5 & & & \\
\hline 6 & $13 / 04$ & & \\
\hline 7 & $14 / 04$ & $\begin{array}{l}\text { Término do estabelecimento e } \\
\text { execução do plano. }\end{array}$ & \multirow{2}{*}{$\begin{array}{l}\text { Organização dos alunos em grupos para a discussão, } \\
\text { elaboração e execução de um plano de resolução. } \\
\text { Escolha de alguns alunos para apresentar suas } \\
\text { soluções em plenária e discussão entre professor e } \\
\text { alunos para formalizar os conceitos inerentes ao } \\
\text { desenvolvimento da proposta. }\end{array}$} \\
\hline 8 & $14 / 04$ & $\begin{array}{l}\text { Retrospecto: momento de discussões } \\
\text { e sistematização de conceitos. }\end{array}$ & \\
\hline
\end{tabular}

Quadro 2: Organização da proposta

Fonte: Os autores.

\footnotetext{
${ }^{5}$ Chamamos de desafios as questões trazidas pelos alunos para as aulas de Matemática, que apresentavam um grau maior de dificuldade e raciocínio, porém embora tenhamos utilizado este termo com os alunos, trataremos as tarefas apresentadas na perspectiva de problema.
} 
Na seção seguinte, apresentaremos o relato da experiênciasobre Resolução de Problemasdesenvolvida em sala de aula. O relato será apresentado com a seguinte estrutura: Etapas da Resolução de Problemas (o relato é apresentado a partir das etapas indicadas por Polya (1994); Números de aulas (cada uma das etapas foi dividida em um certo número de aulas); Problema ou tarefas desenvolvidas (em cada uma das aulas apresentamos o problema gerador e tarefas complementares que foram desenvolvidas com os alunos); falas dos alunos e do professor (apresentamos algumas falas dos alunos ao construírem o seu raciocínio e as falas do professor ao conduzir esse processo) e aspectos relevantes (apresentamos os aspectos positivos e negativos que percebemos e que consideramos relevantes, no decorrer do desenvolvimento de cada etapa).

Para preservar a identidade dos sujeitos da pesquisa, quando uma fala apresentada for de um aluno, ela será representada pela letra A seguida por um número. Entretanto, quando a fala do aluno for relativa a uma tarefa em grupo, ela será representada pela letra A (aluno) seguido da letra $\mathrm{G}$, referente ao grupo que este aluno participava. Assim, $\mathrm{A}_{4} \mathrm{G}_{5}$ representa o aluno 4 do grupo 5. Como só temos o professor de Matemática da turma envolvido na pesquisa, o mesmo será representado por professor.

\subsection{Resolução de problemas - Primeira Etapa: Familiarização e Aperfeiçoamento da compreensão}

A primeira fase da metodologia de Resolução de Problemas compreende a Familiarização e Aperfeiçoamento da compreensão. A familiarização é o primeiro contato do aluno com o problema. Nesse momento o aluno deve compreender o problema de forma geral, considerando os objetivos e dados relevantes. No aperfeiçoamento da compreensão, o problema deve estar claro para o aluno, que deverá ter condições de explicá-lo.

Para que fique claro para o leitor como a experiência foi desenvolvida, faremos a descrição dos fatos pelas aulas utilizadas em cada uma das fases.

\subsubsection{Familiarização - Aula 1}

Como vimos no Quadro 1, a primeira fase, a Familiarização, é o momento do lançamento do problema para que os alunos possam compreender e se familiarizar com o mesmo. Ao professor cabe o papel de escolher um bom problema e motivar os alunos. Iniciamos a aula relatando aos alunos que estudaríamos o conteúdo de múltiplos e 
divisores. Na busca por motivá-los anunciamos o desafio do dia, sem mencionar a sua relação com o novo conteúdo.

O problema apresentado no Quadro 3 foi narrado pelo professor, pois entendemos que isso poderia despertar a curiosidade dos estudantes. Mediante a dificuldade de alguns alunos, procuramos utilizar algumas situações particulares como exemplo, para que estes pudessem fazer algumas associações e entendessem a proposta.

\section{O Problema das portas}

Em um corredor há 900 portas que estão numeradas de 1 a 900, inicialmente todas fechadas. Atravessam o corredor 900 pessoas, também numeradas de 1 a 900 . Sabe-se que:

- A pessoa número 1 movimentará todas as portas que são múltiplas de 1 ;

- A pessoa número 2 movimentará todas as portas que são múltiplas de 2 ; De forma genérica:

- A pessoa número n movimentará todas as portas que são múltiplas de $\mathrm{n}$.

Todas as pessoas (de 1 a 900) irão passar uma única vez pelo corredor de forma sequencial e crescente (1, 2, 3, $4, \ldots, 900)$ e, ao movimentar uma porta a pessoa irá abrir se ela estiver fechada ou fechar se ela estiver aberta. Ao final, quais portas estarão abertas?

Quadro 3: O problema das portas

Fonte: Adaptado de Morgado e Carvalho (2014, p. 122).

Após o relato houve algumas discussões e comentários, fato que nos proporcionou analisar que, de forma geral, a classe se envolveu com o problema. Vejamos alguns trechos das falas dos alunos que caracterizaram esse momento:

$A_{1}$ : Não faço ideia de como descobrir a resposta.

$\boldsymbol{A}_{2}$ : É impossível saber! São muitas portas e muitas pessoas! Vou ter que testar uma por uma?

Professor: Precisamos pensar em todas as portas e em todas as pessoas? E se realizarmos alguns testes para ver o que ocorre?

A $_{3}$ : Acho que deve ter outro jeito, não é possivel ter que fazer o teste com todas as portas.

Os questionamentos e a discussão realizados pelo professor e alunos puderam auxiliar nas etapas de familiarização e compreensão do problema, conforme apresentados por Polya (1994). A sugestão de analisar algumas portas deu aos alunos uma expectativa e também uma possibilidade de iniciar a produção. Podemos destacar ainda que essa discussão coletiva acabou promovendo uma maior comunicação entre alunos e professor.

\subsubsection{Aperfeiçoamento da compreensão - Aulas 2 e 3}

As aulas do dia seguinte iniciaram-se com os questionamentos dos alunos sobre o problema das portas. No momento inicial da discussão, alguns formularam algumas hipóteses. Dentre elas destacamos: 
$A_{5}:$ Eu acho que a resposta é que as portas ímpares estão fechadas e as portas pares estão abertas.

Professor: Vocês acham que está correto o que ele pensou?

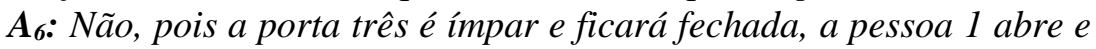
a pessoa 3 fecha.

Identificamos que alguns alunos já tinham compreendido bem a proposta, nos termos que Polya (1994) caracteriza como aperfeiçoamento da compreensão, por outro lado, a maioria ainda estava na etapa de familiarização com o problema.

Analisamos, conforme previamente planejado, que seria necessário que os alunos tivessem experiências com conceitos matemáticos que pudessem auxiliá-los na resolução do problema. Conforme destaca Polya (1994), as ideias para resolução de um problema surgem com base nas suas experiências anteriores, tanto relacionadas a conceitos matemáticos, quanto a resolução de outros problemas similares.

Nesse contexto encaminhamos a aula iniciando os estudos dos conceitos de múltiplos e divisores, buscando explorar a metodologia de Resolução de Problemas apresentada por Polya (1994). De início foi possível percebermos que a tarefa exigia um certo esforço de interpretação dos alunos para formular estratégias, apresentar e argumentar soluções. O Quadro 4 apresenta as tarefas propostas para a aula.

Tarefa 1: Na turma do $7^{\circ}$ ano de um Colégio tem algumas alunas que gostam de inventar mentiras. Sabe-se que a aluna X mente de 2 em 2 dias, a aluna $\mathrm{Y}$ gosta de mentir a cada três dias, e a aluna $\mathrm{Z}$ mente a cada 4 dias. Sabendo que hoje, dia 16/03, as três alunas inventaram uma mentira, qual será o próximo dia em que as três irão mentir juntas novamente?

Tarefa 2: O médico de Carla receitou dois remédios que ela deverá tomar durante uma semana. O primeiro deve ser tomado de 6 em 6 horas e o segundo deve ser tomado de 4 em 4 horas. Carla não consegue acordar de madrugada, então começou a analisar quais seriam os melhores horários para iniciar a medicação. Com base nas informações vamos ajudar Carla a pensar: de quanto em quanto tempo Carla tomará os dois remédios simultaneamente? Existe um melhor horário do dia para que ela inicie o tratamento, de forma que não precise levantar durante a madrugada?

Tarefa 3: Uma empresa aérea oferta alguns voos regulares saindo de Curitiba, observe o roteiro:

Linha A: de Curitiba a Joinville - Voo a cada 2 horas;

Linha B: de Curitiba a São Paulo - Voo a cada 3 horas

Linha C: de Curitiba a Rio de Janeiro - Voo a cada 5 horas.

Sabendo que na quinta-feira (07/04) às 10 horas estavam previstos voos nas três linhas, qual será o próximo dia e o horário em que as três linhas terão voos previstos simultaneamente?

Quadro 4: Tarefas Propostas

Fonte:Os autores

Em seguida, realizamos uma breve discussão sobre a realização das tarefas. Foi possível perceber uma estratégia recorrente na resolução dos alunos, que ao escrever os múltiplos de 2, 3 e 5, estes acabavam encontrando o Menor Múltiplo Comum desses números. Nesse contexto, aproveitamos as discussões para apresentar o conceito de Mínimo Múltiplo Comum (MMC) e sistematizar o algoritmo para a determinação do 
MMC, deixando evidente aos alunos que este algoritmo poderia facilitar a resolução de problemas envolvendo tal conceito.

No fim dessa aula sugerimos aos alunos que refletissem sobre o problema das portas, buscando estabelecer relações com os conceitos abordados durante a aula. O conceito de múltiplos relaciona-se com o aperfeiçoamento da compreensão do problema, visto que o aluno pode entender melhor a relação entre as pessoas e as portas que elas movimentam. Percebemos alguns aspectos positivos ao término dessa aula, que além dos alunos perceberem essa relação, houve um maior envolvimento dos alunos da turma, no processo de resolução do problema.

\section{2 Resolução de problemas - Segunda Etapa: Estabelecendo um Plano}

Segundo Polya (1994), a segunda fase da Resolução de Problemas consiste no estabelecimento de um plano.Portanto, após a compreensão do problema os alunos devem estabelecer um plano de execução, ou seja, desenvolver uma estratégia que lhe permita resolver o problema. No desenvolvimento da experiência aqui relatada, o Estabelecimento do Plano para a resolução do problema consistiu na escolha e verificação de algumas portas, testando-as até que se perceba um padrão. Entretanto, percebemos que os alunos encontraram muitas dificuldades em avançar na questão, por conta da inexperiência ou falta de hábitos de trabalhar com tarefas dessa natureza, pois ao elaborar o plano osalunosdeveriamdistinguir o que fariam em cada um dos passos a serem executados e as estratégias que seriam utilizadas para alcançar esses objetivos.

\subsubsection{Estabelecimento de um plano-Aulas 4 e 5}

Dentro da perspectiva da Resolução de Problemas (POLYA, 1994), buscamos iniciar as aulas 4 e 5, mantendo o diálogo, ouvindo como os alunos construíram o processo de organização de seus raciocínios, apontando as suas expectativas e frustrações ao realizar os testes com portas aleatórias. Em contrapartida analisamos que para a maioria deles a compreensão do problema ( $1^{\text {a }}$ etapa) já estava finalizada, e a dificuldade no estabelecimento do plano de resolução ( $2^{a}$ etapa) era natural, pois conforme destaca Polya (1994), esta etapa demanda certo grau de complexidade.

Nessas duas aulas abordamos o conceito de divisores de modo análogo à aula anterior. Encaminhamos as tarefas buscando motivar os alunos para que pudessem explorar o tema trabalhado, estabelecendo algumas relações e criando conceitos que 
posteriormente foram sistematizados na lousa e, mediante discussão, sistematizamos o algoritmo para o cálculo do Máximo Divisor Comum (MDC). No final da aula oportunizamos um momento de discussão, que foi motivado pelo questionamento apresentado abaixo:

Professor: O conteúdo que estudamos na aula de hoje tem alguma relação com o problema das portas? Fixe o seu pensamento em uma das portas, por exemplo, a porta 20 , quais são as pessoas que moverão tal porta?

Alguns alunos estabeleceram a relação esperada "quem move a porta 20 são os divisores de 20". Novamente foi posta aos alunos a sugestão de fazer os testes, mas agora buscando relacionar o problema com os conceitos de múltiplos e divisores que aprenderam.

Nessas duas aulas também destacamos alguns aspectos positivos, que além dos alunos perceberem essas relações também houve um maior envolvimento destes, no processo de resolução do problema.

\subsubsection{Estabelecimento de um plano-Aula 6}

Na presente aula, já completávamos uma semana da proposição do problema, e tínhamos a maior parte dos alunos envolvida com a resolução do mesmo, entretanto, tínhamos também a preocupação de que o estímulo fosse se perdendo ao longo dos próximos dias. Atrelado a isso, ainda tínhamos a preocupação de chamar a atenção de uma minoria que se mostrava indiferente ao processo de resolução. Enquanto alguns evidenciavam suas tentativas e frustrações ao longo dos últimos dias, outros até se mostravam interessados quando o assunto era o problema, mas via-se que não dedicavam tempo e esforços extras em tentar resolvê-los. Percebemos que estes alunos mesmo fora da sua zona de conforto que era o costume e a praticidade das aulas expositivas, ainda aguardavam que o professor desse a resposta do problema.

Dadas às condições, mudamos um pouco nossas estratégias para as próximas aulas, buscando identificar se algum aluno apresentava algum progresso. Um aluno relatou:

A12: Achei que tinha a ver com as portas que eram números primos, mas acho que estava errado.

Professor: $O$ que vocês percebem com as portas com números primos?

A23: Todas as portas que são números primos estão fechadas.

Professor:Por quê?

$A_{29}$ :Porque os números primos têm apenas dois divisores, uma abre e a outra fecha.

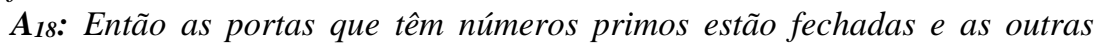
abertas? 
Professor: Todas as portas que não têm números primos estão abertas?

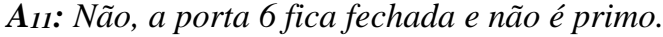

Professor:Vejam, essas ideias são interessantes! É isso aí! Estamos no caminho correto! Falta pouco.

Nesse momento relatamos que, diferente dos outros desafios, na próxima aula trabalharíamos em grupos para que todos tivessem a oportunidade de encontrar uma solução para o problema. E na presente aula retomamos alguns conceitos de múltiplos, divisores, MMC, MDC e sequências numéricas - números pares, ímpares, primos, quadrados perfeitos, bem como suas propriedades.

\subsubsection{Término do Estabelecimento e Execução do plano -Aula 7}

No início da aula um dos alunos comentou ter resolvido o problema. Foi solicitado ao mesmo que justificasse o seu raciocínio para o professor. Vejamos o que o aluno A4 do grupo G5 apresentou como justificativa:

$\boldsymbol{A}_{4} \boldsymbol{G}_{5}:$ Fazendo os testes, vi que a primeira porta que ficará aberta é a porta 1, a segunda é a porta 4, a terceira é a porta 9, a próxima será a 16. Então é só somar os números ímpares.

Professor: Não entendi seu raciocínio, me explique.

Em seguida o aluno mostrou o esquema que tinha feito em seu caderno, Figura 2, que gerou o diálogo:

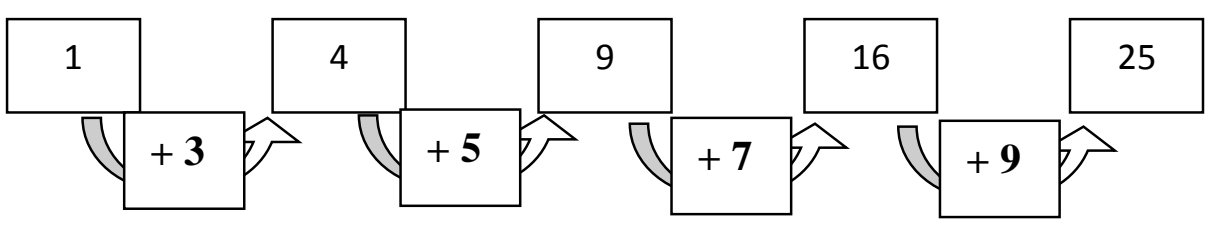

Figura 2: Esquema da resolução do problema pelo aluno

Fonte: Os autores, com base no raciocínio do aluno.

Professor:Parece estar certa sua solução, você me surpreendeu! Eu não tinha pensado no problema dessa forma, é uma solução bem interessante! Quantos testes você fez para ver se estava correto?

$\boldsymbol{A}_{4} \boldsymbol{G}_{5}$ : Eu fiz vários e todos deram certo.

Professor: Vou analisar a resolução e voltamos a conversar.

Era necessário encontrar uma justificativa para o argumento do aluno ou então refutar sua hipótese. Enquanto encaminhamos a organização dos grupos e a entrega das folhas que os auxiliariam no estabelecimento do plano, procuramos estabelecer uma justificativa para a resposta dada pelo aluno que logo ficou evidente. 
O aluno escolheu o número da primeira porta que estava aberta, que era ímpar, mas também quadrado perfeito e somou com a sequência dos números ímpares, a partir do segundo. Logo, temos:

Quadrado perfeito: $\mathrm{n}^{2}$

Sequência dos ímpares a partir do segundo: $2 \mathrm{n}+1$, sendo $n \in N ; n \geq 1$.

Somando as duas expressões obtemos $\mathrm{n}^{2}+2 \mathrm{n}+1=(\mathrm{n}+1)^{2}$, ou seja, dado $n$ qualquer, $n \in N$, ao somarmos o seu quadrado com o número ímpar $(2 n+1)$ obteremos o próximo quadrado perfeito. Se considerarmos todo $n \in N$, a expressão $(\mathrm{n}+1)^{2}$ representa a sequência dos números quadrados perfeitos, exceto zero.

Quadro 5: Uma justificativa para a resolução

Fonte: Os autores.

Em seguida, parabenizamos o aluno pela sua criatividade ao resolver o problema e pedimos que guardasse a sua solução para compartilhar com os colegas em momento posterior. Propomos a ele realizar as tarefas da aula, sendo seu desafio encontrar uma resposta diferente para o problema, fato que o motivou.

Planejamos para a aula uma sequência de tarefas em que os alunos ficariam divididos emsete grupos: cinco com quatro alunos e dois grupos com três alunos. Inicialmente a divisão seria feita pelo professor buscando considerar as diferentes fases em que os alunos se encontravam em relação ao problema, deixando os grupos diversificados, de forma que os colegas pudessem colaborar com aqueles que tinham maior dificuldade. Entretanto, por conta de alguns problemas de relacionamento e pelo desconforto gerado ao propor grupos preestabelecidos, mudamos de opinião e resolvemos deixá-los livres para se organizarem.

I) Verifique quais pessoasmovimentarão cada uma das portas a seguir:

\begin{tabular}{|l|l|l|l|}
\hline Porta 5 & Porta 9 & Porta 16 12 & Porta 21 \\
\hline
\end{tabular}

II) Qual relação podemos estabelecer entre o número da porta e as pessoas que irão movimentar essa porta?

III) Complete o quadro com base na resposta do item I, determinando quais das portas estarão abertas e quais estarão fechadas.

\begin{tabular}{|l|l|l|l|l|l|}
\hline & Porta 5 & Porta 9 & Porta 12 & Porta 16 & Porta 21 \\
\hline Número de pessoas que moveram a porta & & & & & \\
\hline Condição final (aberta ou fechada) & & & & & \\
\hline
\end{tabular}

IV) Qual a relação entre o número de pessoas que movimentam uma porta e a condição (aberta ou fechada) que ela estará no final?

Quadro 6: Aperfeiçoando a compreensão do problema e estabelecendo relações Fonte: Os autores.

Neste momento os estudantes puderam realizar alguns testes, fazer comparações, estabelecer relações e algumas considerações. Durante a execução percorremos os grupos, orientando para que os alunos discutissem e realizassem as tarefas propostas.

Com relação à resposta do item II, evidenciamos que os grupos $\mathrm{G}_{2}, \mathrm{G}_{3}, \mathrm{G}_{5}, \mathrm{G}_{6} \mathrm{e}$ $\mathrm{G}_{7}$ conseguiram estabelecer a relação "quem movimenta a porta de número $n$ são os 
divisores de n". $\mathrm{O}$ grupo $\mathrm{G}_{4}$ apenas referiu-se à quantidade de pessoas que movimentaram cada uma das portas, não estabelecendo a relação e o grupo $G_{1}$ apenas respondeu, equivocadamente, que se referia ao conceito de MDC.

No item IV todos os grupos, com exceção do $\mathrm{G}_{3}$, conseguiram estabelecer a relação esperada "se uma quantidade par de pessoas movimentarem a porta ela ficará fechada e se forem movimentadas por uma quantidade ímpar de pessoas, ficará aberta". $\mathrm{O}$ grupo $\mathrm{G}_{3}$ relatou apenas que a quantidade de portas, que ao final se encontravam abertas, era maior que a quantidade de portas que ficavam fechadas, conforme podemos observar nos relatos:

$A_{1} G_{7}: O$ número de pessoas ímparesdeixaram as portas sempre abertas e as pessoas de número pardeixaram as portas sempre fechadas.

$\boldsymbol{A}_{2} \boldsymbol{G}_{5}:$ Movimentada, um número par estará fechada e número ímpar aberta. $\boldsymbol{A}_{3} \boldsymbol{G}_{6}:$ Todas que terminam em par é fechadae todas que terminam em ímpar é aberta.

$\boldsymbol{A}_{2} \boldsymbol{G}_{3}$ : Menos ficaram abertas e mais fechadas.

Analisando as respostas de $\mathrm{A}_{1} \mathrm{G}_{7}, \mathrm{~A}_{2} \mathrm{G}_{5}$ e $\mathrm{A}_{3} \mathrm{G}_{6}$, percebemos a dificuldade em expressar de forma escrita suas ideias, fato que inferimos ocorrer pela falta de realização desse tipo de tarefa. Se analisássemos apenas o que escreveram, o diagnóstico seria que estão incorretos, porém, o contexto, o desenvolvimento da tarefa e os momentos em que acompanhamos as discussões nos grupos, nos permitiram perceber que eles entenderam e analisaram corretamente a relação existente. Já o grupo $G_{3}$ relatou que o número de portas que ficam abertas é menor que o número de portas fechadas.

Propusemos para a sequência as tarefas do Quadro 7, onde escolhemos 20 portas e as dividimos em 4 grupos, de forma que cada grupo de 5 portas fosse analisado por um aluno. Essa estratégia foi escolhida para garantir que todos os alunos trabalhassem. Então, dentro do grupo estabelecemos uma parte do trabalho para cada um, afirmando que o papel de todos era de extrema importância para a sequência do trabalho.

Ao término dessa etapa os grupos $\mathrm{G}_{4}, \mathrm{G}_{5}$ e $\mathrm{G}_{7}$ conseguiram perceber a relação que permitiria responder ao problema "As portas que ficam abertas são aquelas cujos números são quadrados perfeitos". Vejamos:

$\boldsymbol{A}_{2} \boldsymbol{G}_{7}:$ As portas abertas são um quadrado perfeito e fechadas não.

$A_{2} G_{5}:$ Todos os quadrados perfeitos estarão abertos.

Pedimos aos grupos $\mathrm{G}_{4}, \mathrm{G}_{5}$ e $\mathrm{G}_{7}$ que realizassem mais alguns testes para verificar a relação encontrada enquanto orientávamos os grupos com dificuldades. Como o trabalho em grupo tinha uma parte realizada individualmente, percebemos que alguns alunos tinham analisado incorretamente as suas portas e isso impossibilitou a percepção 
da relação. Nesses casos pedimos aos alunos que refizessem os testes. Nos grupos que ocorreram muitos erros pedimos para que os alunos trocassem o grupo de portas às quaistinham ficado responsáveis, para conferir os cálculos dos colegas e constatar os erros.

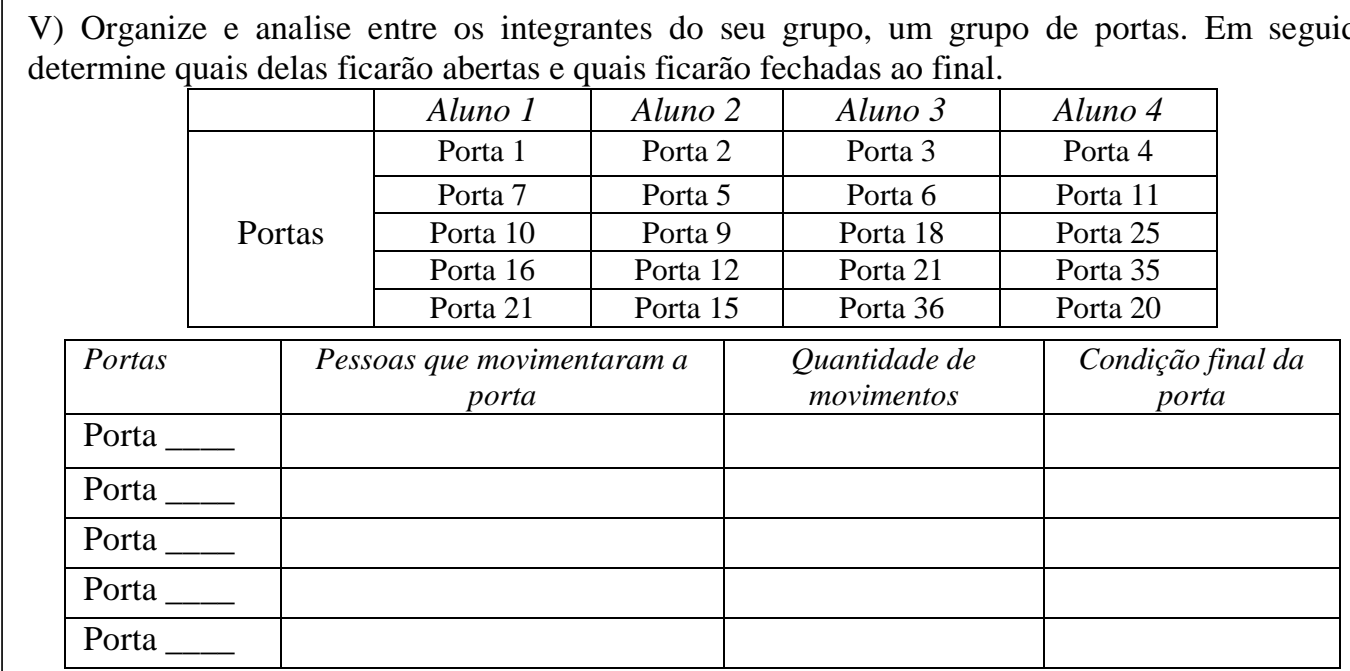

VI) Agora reúna os resultados encontrados por seu grupo e complete o quadro determinando quais portas estarão abertas e quais estarão fechadas.

\begin{tabular}{|c|c|}
\hline Portas Abertas & Portas Fechadas \\
\hline & \\
\hline
\end{tabular}

Quadro 7: Estabelecendo um plano de resolução Fonte:Os autores.

\subsection{Retrospecto - Quarta Etapa}

Segundo Polya (1994), na fase do retrospecto os estudantes devem procurar rever suas soluções, verificar todas as etapas, conferindo se existem erros.Se for possível, conferir os resultados, analisar se existem maneiras diferentes para resolver o problema e buscar relacioná-lo com outros problemas e/ou conceitos matemáticos.

\subsubsection{Momento de discussão, retrospecto e sistematização dos conceitos - Aula 8}

Mesmo após a realização das tarefas propostas na aula 7, alguns grupos não estabeleceram uma relação que permitisse responder ao problema. Propusemos um momento de discussão coletiva para oportunizar aos alunos relatar suas experiências e auxiliar os colegas que encontraram dificuldades. Mediamos as discussões por meio de alguns questionamentos, como os apresentados abaixo: 
Professor: $O$ que vocês perceberam após a realização dos testes com as portas?

A13: São quadrados perfeitos.

Professor: $O$ que são números quadrados perfeitos?

A13: São números, assim: $1 \times 1=1,2 \times 2=4,3 \times 3=9$ e assim por diante.

A13: São números que têm raiz quadrada.

Professor: Quais números não têm raiz quadrada?

A13: Quis dizer que os quadrados perfeitos são números que têm raiz quadrada exata!

Professor: É possível dizer quantas portas ficarão abertas?

A13: São muitas!

Professor: Qual é a última porta que ficará aberta? Qual é o quadrado que gera esse número?

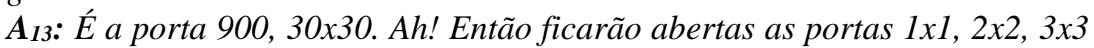
e assim por diante, até chegar na porta 30x30. Serão 30 portas abertas.

Percebemos que os alunos apresentavam dificuldades em relação à sequência dos números quadrados perfeitos, porém a discussão oportunizou uma melhor compreensão da resolução do problema. Propusemos que, em grupos, escrevessem suas conclusões, orientando-os a partir das questões apresentadas no Quadro 8.

VII) Percebeu algum padrão em relação à condição final das portas? Você consegue responder quais portas estarão abertas e quais portas estarão fechadas?

VIII) Considerando uma porta qualquer, podemos estabelecer uma regra para dizer se a porta estará aberta ou fechada ao final do processo?

IX) Quais conceitos matemáticos estão envolvidos no processo de resolução desse problema?

X) Que propriedade matemática obtemos por meio da resolução desse problema? Descreva com suas palavras.

Quadro 8: Estabelecendo e generalizando conceitos

Fonte: Os autores.

O principal objetivo da tarefa proposta no Quadro 8 era analisar se os alunos conseguiriam relacionar o problema aos conceitos matemáticos dele decorrentes. A proposta desse momento também oportuniza a reflexão e avaliação do trabalho docente, pois os relatos dos alunos poderiam nortear o planejamento de recuperação dos conteúdos.

Apresentamos abaixo os relatos dos grupos relativo às questões do Quadro 8.

- Questões VII e VIII

$G_{1:}$ Todas as portas pares estão fechadas e as que mexem um número de vezes impar estão abertas. As portas que forem um quadrado perfeito estarão abertas e que não forem estarão fechadas.

$\boldsymbol{G}_{2}$ : Quadrado perfeito ABERTAS = 9, 36, 1, 16, FECHADAS = 2, 5, 12, 15, $21,18,6,3,7,10,21$. Se ela for quadrado perfeito estará aberta e se não for estará fechada.

G3: Menos aberta e mais fechada.

$G_{4}:$ Quando são um quadrado perfeito, as portas estão abertas $(1,4,9,25,36)$ e fechadas quando não são $(2,5,12,15,7,10,16,21,3,6,18,21,11,35,20)$. G5: Que se o número da porta for quadrado perfeito a porta estará aberta. 
G6: Aberto: 36, 9, 1, 16, 36, 4, 25, 20. Fechadas 3, 6, 8, 21, 25, 12, 15, 7, 10. G7: Sim, sempre o número de pessoas ímpares deixarão as portas abertas e os pares deixarão as portas fechadas. As portas abertas são um quadrado perfeito e fechadas não.

$\mathrm{Na}$ resposta do grupo $\mathrm{G}_{1}$ identificamos que na sentença "todas as portas pares estão fechadas", os alunos se referiam a "todas as portas que foram mexidas uma quantidade par de vezes ficarão fechadas". No grupo $\mathrm{G}_{7}$ percebemos que, embora tenham compreendido a relação, os alunos tiveram dificuldades para relatar de forma escrita.

Nos relatos de $\mathrm{G}_{3}$ e $\mathrm{G}_{6}$ identificamos que, mesmo após o processo, os grupos não estabeleceram a relação que permitia responder ao problema. Percebemos na resposta de $\mathrm{G}_{6}$ a porta 20 classificada incorretamente como aberta, porém as demais estavam certas. Já o grupo $\mathrm{G}_{3}$ só respondeu, novamente, que haveria mais portas fechadas do que abertas.

- Questão IX:

Gı: Os divisores, os primos, MMC, quadrado perfeito e os múltiplos.

$\boldsymbol{G}_{2}:$ Quadrados perfeitos, números ímpares e pares e os divisores.

$\boldsymbol{G}_{4}: M M C$, múltiplos, quadrado perfeito, primos, divisores.

G5: Usamos os quadrados perfeitos para saber se estava aberta ou fechada.

$G_{6}:$ Que a gente tinha que ver quais portas estavam abertas ou fechadas.

$\boldsymbol{G}_{3} \boldsymbol{e} \boldsymbol{G}_{7}:$ não responderam ao questionamento.

A questão IX tinha como objetivo perceber se os alunos estabeleceram relações entre o problema e os conceitos matemáticos utilizados na resolução. Ao analisarmos a resposta dos grupos $\mathrm{G}_{3}, \mathrm{G}_{6}$ e $\mathrm{G}_{7}$ podemos observar que eles não conseguiram identificar tais relações.

- Questão X:

$G_{I}:$ Que para sabermos que estão abertas ou fechadas temos que saber se é um quadrado perfeito.

$G_{2}:$ A relação é que o quadrado perfeito é um número de divisores ímpares.

G3: Não respondeu ao questionamento.

G4: $O$ quadrado perfeito é igual aos divisores ímpares.

G5: Que os quadrados perfeitos têm um número ímpar de divisores.

G6: Que ficaram umas fechadas e outras abertas.

$G_{7}:$ É um quadrado perfeito.

A questão $X$ tinha por objetivo sistematizar o conceito matemático decorrente da resolução do problema. Isso pode ser constatado na resposta dos grupos $\mathrm{G}_{2}, \mathrm{G}_{4}, \mathrm{G}_{5}$ : “Os números quadrados perfeitos possuem uma quantidade ímpar de divisores”. Entretanto, observamos, com base nas discussões no momento da proposta, que os grupos $\mathrm{G}_{1}$ e $\mathrm{G}_{7}$ compreenderam os conceitos, mas não conseguiram apresentar tal sistematização e os grupos $\mathrm{G}_{3}$ e $\mathrm{G}_{6}$ não estabeleceram uma relação e uma sistematização para a proposta. 
Após o momento de discussões convidamos o aluno $\mathrm{A}_{4} \mathrm{G}_{5}$, que havia resolvido o problema de modo diferente, para fazê-lo na lousa e, em seguida, houve um debate onde as opiniões dos alunos divergiram em relação a qual das duas soluções era a mais fácil.

Para finalizar a aula recolhemos as tarefas realizadas pelos grupos e fizemos, juntamente com os alunos, um resumo dos conceitos e propriedades que abordamos durante o processo de Resolução de Problemas. Realizamos, ainda, uma breve avaliação do trabalho, onde os alunos puderam expor suas opiniões sobre a proposta. Os alunos se revelaram motivados mediante as descobertas e, ao questionarmos se gostariam de realizar mais tarefas nesse formato, responderam que sim.

Com o objetivo de preparar os alunos para resolver o problema inicial, mais complexo, apresentamos, a partir da metodologia de Resolução de Problemas, alguns problemas mais simples, como os do Quadro 4. Isso possibilitou que eles relacionassem, utilizando diferentes estratégias os conceitos de MMC e MDC à resolução do problema inicial.

\section{Considerações finais}

Com base nos argumentos e discussões desenvolvidas na última etapa, percebemos uma evolução em relação ao desenvolvimento de raciocínio e habilidades dos alunos em resolver problemas e também um grande envolvimento por parte da maioria dos estudantes da classe, fato que não ocorria nas aulas anteriores. Tais fatores são alguns dos aspectos positivos, frutos da experiência com o trabalho que planejamos.

Outro fator preponderantemente positivo foi a escolha de trabalhar um novo conteúdo matemático, partindo de um problema que gerou o estudo de conceitos que puderam ser compreendidos por meio daresolução desse problema e culminou com a sistematização de uma propriedade, referente aos números quadrados perfeitos no presente estudo. Essa abordagem, em nossa concepção, possibilitou uma aprendizagem mais significativa aos alunos, pois estes puderam elaborar e encontrar sentido para o raciocínio construído durante a resolução do problema.

Apontamos como importante no processo, o Modelo proposto por Polya, considerando a imaturidade da turma no processo de resolução de problemas. Além das quatro etapas de resolução de problemas que embasaram nosso trabalho, utilizamos as recomendações do autor para encaminhar as aulas, como por exemplo: I) a resolução de problemas mais simples, que podem relacionar-se com o problema geral; II) estabelecer 
relação entre o problema e conceitos matemáticos; III) pensar em situações específicas do problema para depois generalizar um conceito; e, IV) após a resolução do problema retornar a ele analisando as soluções, suas variações e confrontando as diferentes resoluções.

Em contrapartida, analisamos alguns fatores negativos no desenvolvimento da proposta, aos quais podemos considerar as experiências, que servirão de base para o planejamento de outros trabalhos. Dentre estes destacamos a forma de organização dos grupos, que por ter sido livre ocasionou alguns problemas, como, por exemplo, a não conclusão da tarefa (grupo $\mathrm{G}_{3}$ ), e a falta de comprometimento de alguns alunos que atrapalharam os grupos e acabaram alongando a tarefa, como ocorreu nos grupos $\mathrm{G}_{3}, \mathrm{G}_{6}$ e G7. Acreditamos que se tivéssemos mantido nossa forma de organização dos grupos por seleção e apenas trocado alguns estudantes, poderíamos ter obtido resultados melhores. Entretanto, cabe ressaltar que observamos que a capacidade dos mesmos em trabalhar em grupo foi aprimorada, a partir da tarefa de resolver problemas mais desafiadores.

A principal lição extraída dessa experiência foi a efetividade desse método em aprimorar o raciocínio lógico e a criatividade entre os alunos. Nesse contexto é que apresentamos o nosso relato de experiência, em que objetivamos trazer uma dinâmica diferente às aulas, considerando estratégias metodológicas que são desenvolvidas por pesquisadores do campo da Educação Matemática, mas adequando-a às condições e às especificidades da turma em que trabalhamos, para posteriormente apresentarmos os resultados que refletem a realidade, evidenciando aspectos positivos e negativos que ocorreram ao longo do processo, deixando a experiência do trabalho como reflexão aos docentes de Matemática da Educação Básica e também aos acadêmicos que desenvolvem pesquisas em Educação Matemática.

\section{Referências}

BRASIL. Secretaria de Educação Fundamental. Parâmetros Curriculares Nacionais: Matemática. Brasília: MEC/SEF, 1998.

JESUZ, D. A. F. de.; OLIVEIRA, J. C. R. de.; TORTOLA, E. Uma proposta para o ensino do teorema de bayes na perspectiva da resolução de problemas. In: ENCONTRO NACIONAL DE EDUCAÇÃO MATEMÁTICA, 12, 2016, São Paulo. Anais... São Paulo: Universidade Cruzeiro do Sul, 2016. p. 1-12. Disponível em:

<http://www.sbembrasil.org.br/enem2016/anais/pdf/7478_3221_ID.pdf>. Acesso em: 30 abr. 2018

MORGADO, A.C.; CARVALHO, P.C.P. Matemática Discreta: Coleção PROFMAT. Rio de Janeiro: SBM, 2014. 
PARANÁ (Estado). Secretaria de Estado da Educação. Diretrizes Curriculares da Educação Básica de Matemática. Curitiba: SEED, 2008.

POLYA, G. A Arte de Resolver Problemas. Rio de Janeiro: Interciência, 1994.

PONTE, J. P. Tarefas no ensino e naaprendizagem da matemática. In: PONTE, J. P. (Org.). Práticas profissionais dosprofessores de matemática. Lisboa: Instituto de Educação da Universidade de Lisboa, 2014. p. 13-27.

SCHOENFELD, A. H. Heurísticas da sala de aula. In: KRULIK, S.; REYS, R. E. A Resolução de Problemas na matemática escolar. São Paulo: Atual, 1997.

VAN DE WALLE, J. A. Elementary and Middle School MathemaTIC. 4. ed. New York: Longman, 2001.

Recebido em: 13 de abril de 2018.

Aceito em: 25 de abril de 2018. 